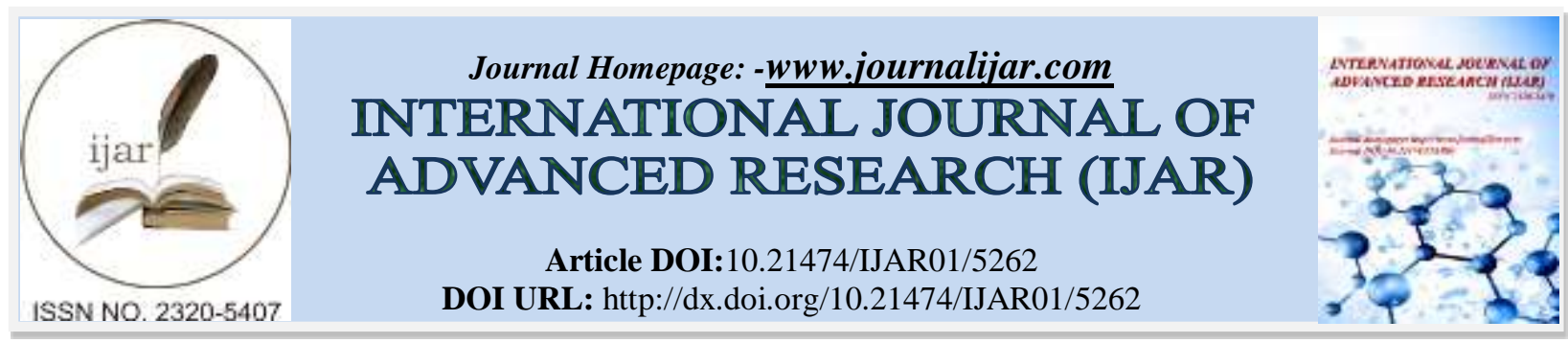

RESEARCH ARTICLE

\title{
THE KNOWLEDGE AND PRACTICE OF FORENSIC DENTISTRY AMONG DENTAL PRACTITIONERS IN THE EASTERN PROVINCE, SAUDI ARABIA.
}

\author{
Al-Khalaf. A $\mathbf{H}^{1}$, Al Nahawi D E ${ }^{1}$, Al Naser $H_{H^{1}}$ and Nazir $M A^{2}$. \\ 1. Dentist, Ministry of Health, SAUDI ARABIA \\ 2. Public Health, Preventive Dental Sciences, IMAM ABULRAHMAN BIN FAISAL UNIVERSITY, \\ DAMMAM, SAUDI ARABIA
}

\section{Manuscript Info}

Manuscript History

Received: 23 June 2017

Final Accepted: 25 July 2017

Published: August 2017

Keywords:

Forensic dentistry; forensic odontology;

knowledge and practice; Saudi Arabia.

\section{Abstract}

Objective: To evaluate knowledge and practice of forensic dentistry among dental practitioners working in the Eastern province, Saudi Arabia.

Materials and methods: Cross-sectional, descriptive study was conducted through a self-administered questionnaire among a sample of 323 dentists working in the Eastern province, Saudi Arabia. Simple descriptive statistical analyses performed to calculate means, standard deviations and frequency distributions. Inferential statistical analyses involved using Pearson's Chi-square test and comparing proportions of various categorical variables between private and governmental dentists. Statistical significance determined at p-value less than 0.05 .

Results: In our study $73 \%$ of the participants considered themselves to have inadequate knowledge about forensic dentistry. More than twothirds of the participants have not been trained in forensic dentistry during their undergraduate program. Regarding the practice of forensic dentistry, only $10 \%$ of the participants handled cases of forensic dentistry. Less than 5\% appeared in courts to provide evidence related to forensic dentistry cases. Regarding records keeping, $88.6 \%$ indicated that they are maintaining dental records for different duration. No forensic dentistry education was described to be the most common cause not to maintain dental records. In comparison, statistically significant differences between private and government practitioners were found with regard to investigation of bite mark patterns and maintaining dental records.

Conclusions: Knowledge and practice of forensic dentistry was inadequate among dental practitioners in the Eastern Province, Saudi Arabia. Statistically significant differences between governmental and private dentists were found with regard to investigation of bite mark patterns and maintaining dental records. The most common barrier to maintaining the dental records was the lack of forensic dentistry education. 


\section{Introduction:}

Forensic dentistry involves the evaluation of injuries to the oral cavity as a result of trauma, accidents, abuse, crimes and calamities, and helps in the investigation of criminal, civil and medicolegal cases (Al Sheddi \& Al Asiri, 2014). This also helps in the recognition of dead individuals by comparing ante and postmortem dental records (Nagarajappa, 2014). We can use teeth to estimate the age of the deceased individuals especially children (Devadiga, 2014). The teeth are one of the human remains that together with different oral habits provide an oral environment as fingerprint unique to each individual which is particularly useful in the identification of deceased individuals (Nagarajappa, 2014). The first case of identification of an individual using dentition was in India in 1191 where a dead king was recognized by his false anterior teeth (Sharma, 2015).

Patient dental records are important documents related to the history of patient, clinical examination, management and prognosis of disease, which can be presented as evidence in the court of law (Charangowda, 2010). It is legal and ethical responsibility of dentists to maintain dental records in their clinics (Devadiga, 2014). Dental practitioners can play an effective role in forensic odontology by maintaining securely retained dental records. Maintaining antemortem records can help recognize human remains (Sharma, 2015). The dramatic increase in the road accidents, violence, crimes and causalities make the maintenance of dental records very important in clinical practice (Nagarajappa, 2014). According to the Indian Dental Association, dental records should be maintained for five years to protect the practitioner against medicolegal issues (Sharma, 2015). The National Health Service (NHS) recommends that dental records be maintained for about 11 years in case of children and adults in England (Devadiga, 2014).

A study conducted in Riyadh, Saudi Arabia, by Al Sheddi et al. (2015) on 248 dentists, reported that 44\% of the dentists maintained dental records for unlimited time and $25.8 \%$ for a specific period. Up to $42.9 \%$ of them received no undergraduate forensic odontology education, and $95 \%$ did not obtain post-graduate training. Sharma et al. (2015) revealed that only $11 \%$ general dentists and $23 \%$ specialist dental practitioners maintained dental records in their clinics. About $98.4 \%$ of general dentists and $90 \%$ of specialist dental practitioners said that their knowledge regarding forensic odontology was inadequate, and majority of them did not know the significance of maintaining dental records for forensic purpose. Al-Azri et al. (2015) showed that dentists were aware of forensic odontology applications (mean score 4.58/6), and majority of respondents $(80.7 \%$ ) thought that the records would be helpful in medicolegal cases. However, increased workload, lack of time and limited storage space were identified as the barriers to keeping accurate and complete dental records. The results acquired by Harchandani et al. (2014) showed $70 \%$ of the dental practitioners maintaining dental records in their clinics/workplaces. On the other hand, Nagarajappa et al. (2014) found that only $12.2 \%$ of the participants kept dental records for more than three years.

Given the importance of maintaining dental records for forensic purposes, data about the awareness of dentists about forensic odontology is sparse in Saudi Arabia. No study was conducted to explore the differences in the knowledge and practice of forensic dentistry between private and governmental dental practitioners in the country.

The objectives of this study are to evaluate the knowledge and practice of forensic dentistry among dental practitioners in the Eastern Province, Saudi Arabia, compare the knowledge and practice of forensic dentistry between governmental and private dental practitioners and identify the barriers to maintaining patients' dental records.

\section{Materials and methods:}

Cross-sectional, descriptive study was conducted and a sample of 323 dentists was calculated. The estimation of sample was based on the total number of dentists working in the Eastern province (population size), 95\% confidence interval, anticipated frequency of outcome in the population and design effect (Schaeffer, Mendenhall \& Ott, 1990). The sample calculations yielded a sample size of 323 dentists and the number was increased to 350 to compensate for non-response, missing information and data entry errors.

The private and governmental sector dentists working in urban and rural areas of the Eastern province were invited to participate in the study. Dental students and dental interns were not included in the study. A list of dentists working in the province was collected and equal number of private and government dentists were randomly selected using MS Excel 2010. 
Data was collected by self-administered questionnaire. Information obtained through literature review was used to draft initial version of the questionnaire (Al Sheddi, \& Al Asiri, 2015; Al-Azri, Harford, \& James, 2015;Harchandani et al., 2014; Nagarajappa, 2014; Sharma, 2015). Subsequently, the questionnaire was reviewed by the dental public health professionals to improve its validity. Pilot test of the final draft of the questionnaire involved 17 practicing dentists. The piloting helped determine acceptability of the questionnaire, improve its reliability, estimate the time required to administer the questionnaire and assess feasibility in conducting the research project (Radhakrishna, 2007). The administration of pilot tested questionnaire started in the February and ended in March 2016. Three visits made to ensure good response rate.

There are four sections in the questionnaires. The first section inquires respondents about the demographic data including years of clinical experience, place and type of job, and nationality. There are about ten questions in the second section, which seek to get information about knowledge of dentists about forensic dentistry. The third section includes six questions about the practice of forensic dentistry such as handling forensic cases, providing evidence in the court, and maintaining dental records. The questions about the barriers to maintaining dental records are sought in the last section of the questionnaire.

The participants of the study were informed about the purpose and objective of the research and informed consents was obtained from them. The confidentiality and privacy of participants were maintained during the administration of questionnaire, data analysis and interpretation of the results.

Data was entered in Statistical Package for Social Sciences (Version 22.0, SPSS Inc., Chicago, IL). Simple descriptive statistical analyses was performed to calculate means, standard deviations and frequency distributions. Accordingly, tables and figures were generated to display various variables of the study. Inferential statistical analyses involved using Pearson's Chi-square test and comparing proportions of various categorical variables between private and governmental dentists. Statistical significance was determined at p-value less than 0.05.

\section{Results:}

A total of 234 participants completed and returned the survey (the response rate is $72.5 \%$ ). Male participants $(60.7 \%)$ were more than female (39.3\%). On the other hand, Saudi respondents were less than non-Saudi with the ratio of 1:1.5. Almost, half of the respondents were general practitioners (47.9\%) followed by specialist (38.0\%) then consultants $(14.1 \%)$. Approximately, equal numbers of private $(\mathrm{N}=128)$ and governmental $(\mathrm{N}=106)$ dental practitioners took part in the study. The mean years of clinical experience was $10.45 \pm 7.85$ (range from 0-39)

Table 2 shows details about the knowledge of forensic dentistry. Lack of knowledge was evident in different aspects of forensic dentistry. $74.7 \%$ considered themselves to have inadequate knowledge about forensic dentistry and only $23.1 \%$ updated their knowledge about forensic dentistry, with Internet being the most common method of updating the knowledge followed by books then scientific journals (as illustrated in chart 3). More than two-thirds of the participants have not been trained in forensic dentistry during their undergraduate program. In contrast, majority of dentists were aware of the significance of maintaining dental records in forensic dentistry and capable to estimate dental age. Furthermore, $64.5 \%$ were able to investigate bite mark patterns and 53.4 percent knew that they could work as experts to provide forensic dental evidence in courts. $80.3 \%$ reported not having established protocols for the management of suspected cases of child abuse.

Regarding the practice of forensic dentistry, table 3 shows a very low level of forensic dentistry practice among the participants. Only $11.5 \%$ handled cases of forensic dentistry and $1.7 \%$ participated as members of forensic team in Ministry Of Health. Less than 5\% appeared in courts to provide evidence related to forensic dentistry cases. Regarding records keeping, $88.5 \%$ indicated that they are maintaining dental records for different duration. The most frequently maintained records are patient's information sheets, radiographs and medical history form. The lowest percentage (42.70\%) was given to the maintenance of dental photographs and investigation reports (as shown in chart 1).

Chart 2 shows the barriers to maintain dental records. No forensic dentistry education was described to be the most common cause not to maintain dental records $(58.1 \%)$ followed by lack refresher courses $(41.9 \%)$ and increasing workload $(41.0 \%)$. In contrast, lack of computer facilities took the lowest percentage (26.50\%).

In comparison, statistically significant differences were found between private and government practitioners with regard to investigation of bite mark patterns and maintaining dental records (as shown in table 4,5) 


\section{Discussion:}

Forensic dentistry is important in solving some law cases such as identification of deaths and abuse cases. Dental tissues can resist difficult situations and it can be a good source for DNA (Preethiet al 2011). In addition, Dental records including but not limited to radiographs, photographs, and dental casts can be highly valuable in the field of FD. For that, knowledge and good record keeping practices is essential not only for forensic dentists, but for all health practitioners.

Current study was conducted to assess knowledge and practice of FD among the practicing dentists in Eastern Saudi Arabia. The results indicated that the majority of the participating dentists in this study are aware of the significance of forensic dentistry. But they do not have adequate knowledge and do not update their knowledge about forensic dentistry. As a result of this, only minority of the participants were handling cases of forensic dentistry and few are members of forensic team in $\mathrm{MOH}$. The dentists indicated that this could be because they have not been exposed to forensic education.

On our study the majority of the dental participants (82.9\%) were aware of the significance of FD, and about $(88.5 \%)$ of dentists maintained dental records. Similarly, Narendra, 2014 showed that $(80 \%)$ of dental practitioners were aware of the significance of FD. Nagarajappa et al, 2014 reported that (93.9\%) of dental practitioners maintained dental records.

Al- Azri, 2015 reported that (21.1\%) of dental practitioners had training in FD and increased workload is the most common barrier to maintaining dental records, while our study found that $(30.3 \%)$ of the participants had training in FD and lack of education about FD is the most common barrier. Present study found (11.5\%) of dentists handle forensic dentistry cases. Similarly, only (4.3\%) of dentists handled such cases in Riyadh, Saudi Arabia (Manal, 2015).

The reasons behind low knowledge of forensic dentistry could be summarized as the lack of education and training in this field during undergraduate programs, also most of the seminars, lectures and courses in our area do not give an attention or opportunity to this field. The low practice rate of forensic dentistry also could be attributed to the negligence of this field from the courts in our area because they are more focusing and depending on forensic medicine, also lack of the training centers and the investigatory equipment which needed for the practice of this field could be addressed as a contributing factor.

The limitations of the current study include that the data were collected through a self-administered questionnaires, which can result in over or under estimation. The response rate was another issue, because dentists were busy and difficult to approach them. Lack of knowledge about the importance of FD could contribute to the limited response rate. Our questionnaire was asking about the knowledge related to forensic dentistry in general without testing the participant skills.

A standardized computerized system for patients record keeping including patient personal information, medical and dental history, dental radiographs, dental photographs casts and bite marks should be established. The universities should give more attention to this field by integrating theoretical and practical courses of forensic dentistry in the undergraduate courses. Also, the ministry of health should establish (commission, board, and committee) that specialized in forensic dentistry in which it can train and provide seminars and lectures about this field. Courts should accredit this field as a source of supporting evidence and ask for it when needed. Future studies should include other provinces of the Kingdom and may be other countries for generalizability.

\section{Conclusion:}

In conclusion, knowledge and practice of forensic dentistry was inadequate among dental practitioners in the Eastern Province, Saudi Arabia. Statistically significant differences between governmental and private dentists were found with regard to investigation of bite marks patterns and maintaining dental records. The most common barrier to maintaining dental records was the lack of forensic dentistry education. Training in forensic dentistry in the undergraduate program and providing more continuing education seminars should be considered to address this deficiency. 
Table 1: Personal information of the participants.

\begin{tabular}{|l|l|l|}
\hline Variable & $\mathrm{N}(\%)$ \\
\hline Male & \multicolumn{2}{c|}{ Gender } \\
\hline Female & \multicolumn{1}{|c|}{$92(39.3)$} \\
\hline \multicolumn{2}{|c|}{ Nationality } \\
\hline Saudi & $91(38.9)$ \\
\hline Non-Saudi & $143(61.1)$ \\
\hline \multicolumn{2}{|c|}{ Qualification } \\
\hline General dentist & $112(47.9)$ \\
\hline Specialist & $89(38.0)$ \\
\hline Consultant & $33(14.1)$ \\
\hline \multicolumn{2}{|c|}{ Type of job } \\
\hline Governmental & $106(45.3)$ \\
\hline Private & $128(54.7)$ \\
\hline
\end{tabular}

Table 2: Knowledge about forensic dentistry.

\begin{tabular}{|l|l|}
\hline Variable & $\mathrm{N}(\%)$ \\
\hline Awareness of the significance of maintaining dental records in forensic dentistry & $194(82.9)$ \\
\hline Knowledge to estimate dental age & $201(85.9)$ \\
\hline Investigation of bite mark patterns & $151(64.5)$ \\
\hline Working as expert to provide forensic dental evidence in court & $125(53.4)$ \\
\hline Identification of domestic violence & $134(57.3)$ \\
\hline Identification of child abuse & $152(65.0)$ \\
\hline Protocol for the management of child abuse & $46(19.7)$ \\
\hline Adequate knowledge about forensic dentistry & $59(25.2)$ \\
\hline Undergraduate training in forensic dentistry & $71(30.3)$ \\
\hline Updating knowledge about forensic dentistry & $54(23.1)$ \\
\hline
\end{tabular}

Table 3: Practice of forensic dentistry.

\begin{tabular}{|l|l|}
\hline Variable & $\mathrm{N}(\%)$ \\
\hline Handling cases of forensic dentistry & $27(11.5)$ \\
\hline Member of forensic team in MOH & $4(1.7)$ \\
\hline Appearing in court to provide evidence & $10(4.3)$ \\
\hline Regulatory requirement to maintain records & $160(68.4)$ \\
\hline Maintaining dental records in the clinic & $207(88.5)$ \\
\hline Duration of maintaining dental records & $47(20.1)$ \\
\hline Less than 2 years & $64(27.4)$ \\
\hline 3-5 years & $46(19.7)$ \\
\hline 7 to 9 years & $77(32.9)$ \\
\hline More than 9 years & \\
\hline
\end{tabular}


Chart 1: Dental Records Maintained by Dentists.

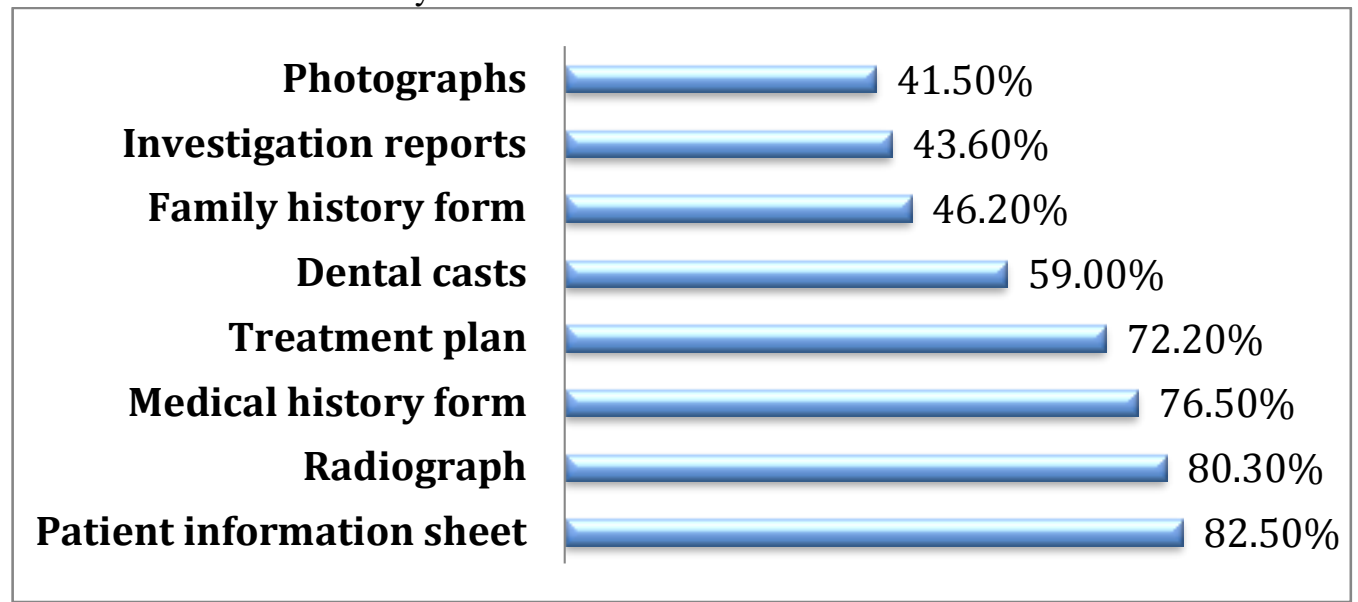

Chart 2: Barriers to maintaining dental records.

\begin{tabular}{|c|c|}
\hline Lack of computer facilities & $26.10 \%$ \\
\hline Lack of time & $29.50 \%$ \\
\hline No regulatory requirement & $32.90 \%$ \\
\hline Lack of storage space & $38.50 \%$ \\
\hline Lack of qualified staff & $40.20 \%$ \\
\hline Increased workload & $41.00 \%$ \\
\hline Lack of refresher courses & $41.90 \%$ \\
\hline No forensic Dentistry Education & $58.10 \%$ \\
\hline
\end{tabular}

Chart 3: Methods of updating knowledge about forensic dentistry.

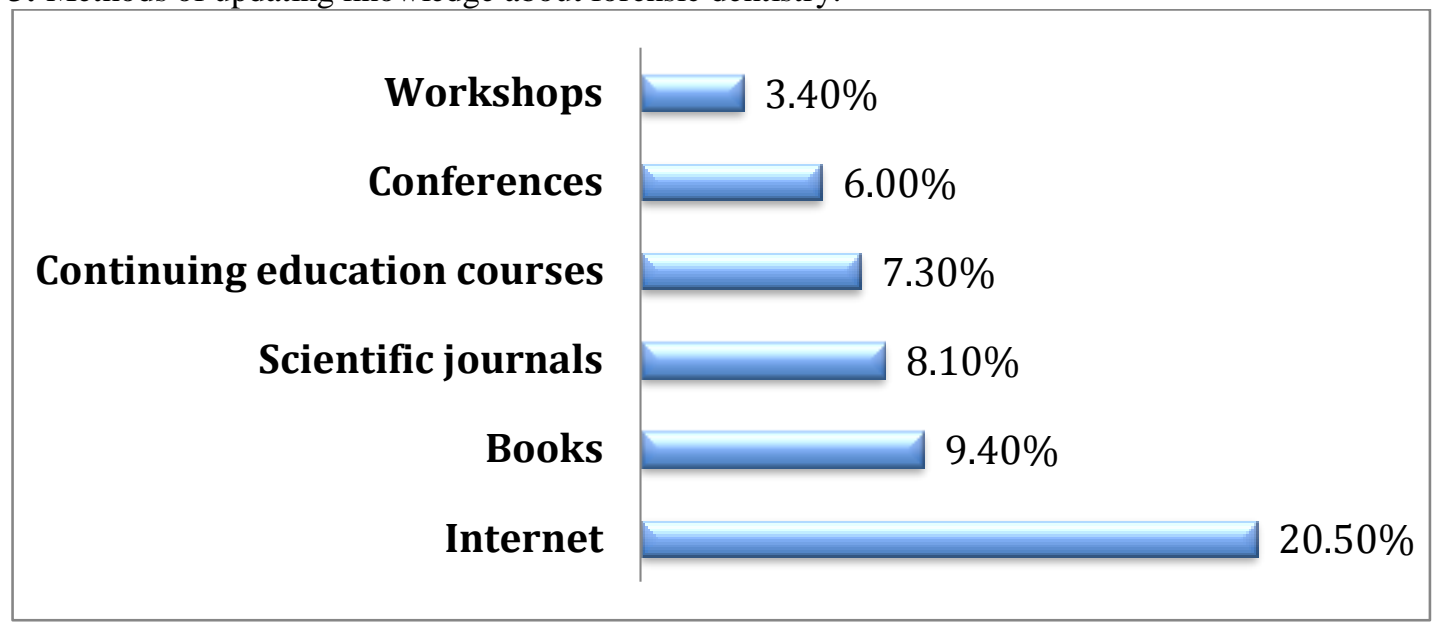


Table 4: Comparison between governmental and private practitioners about the knowledge of forensic dentistry

\begin{tabular}{|l|l|l|l|}
\hline Variable & Government & Private \\
\cline { 2 - 3 } & $\mathrm{N}(\%)$ & $\mathrm{N}(\%)$ \\
\hline $\begin{array}{l}\text { Awareness of the significance of maintaining dental } \\
\text { records in forensic dentistry }\end{array}$ & $90(46.4)$ & $104(53.6)$ \\
\hline Knowledge to estimate dental age & $87(43.3)$ & $114(56.7)$ & 0.126 \\
\hline Investigation of bite mark patterns & $59(39.1)$ & $92(60.9)$ & 0.010 \\
\hline $\begin{array}{l}\text { Working as expert to provide forensic dental evidence in } \\
\text { court }\end{array}$ & $52(41.6)$ & $73(58.4)$ & 0.223 \\
\hline Identification of domestic violence & $54(40.3)$ & $80(59.7)$ & 0.075 \\
\hline Identification of child abuse & $67(44.1)$ & $85(55.9)$ & 0.610 \\
\hline Protocol for the management of child abuse & $20(43.5)$ & $26(56.5)$ & 0.782 \\
\hline Adequate knowledge about forensic dentistry & $24(40.7)$ & $35(59.3)$ & 0.410 \\
\hline Undergraduate training in forensic dentistry & $29(40.8)$ & $42(59.2)$ & 0.366 \\
\hline Updating knowledge about forensic dentistry & $22(40.7)$ & $32(59.3)$ & 0.443 \\
\hline
\end{tabular}

Table 5: Comparison between governmental and private practitioners about the practice of forensic dentistry.

\begin{tabular}{|l|l|l|l|}
\hline Variable & Government & Private & P-value \\
\cline { 2 - 3 } & $\mathrm{N}(\%)$ & $\mathrm{N}(\%)$ & \\
\hline Handling cases of forensic dentistry & $14(51.9)$ & $13(48.1)$ & 0.467 \\
\hline Member of forensic team in MOH & $2(50.0)$ & $2(50.0)$ & 0.849 \\
\hline Appearing in court to provide evidence & $6(60.0)$ & $4(40.0)$ & 0.340 \\
\hline Regulatory requirement to maintain records & $76(47.5)$ & $84(52.5)$ & 0.320 \\
\hline Maintaining dental records in the clinic & $88(42.5)$ & $119(57.5)$ & 0.018 \\
\hline
\end{tabular}




\section{References:}

1. Al-Azri, A. Harford, J. James, H. (2015) Awareness of forensic odontology among dentists in Australia; are they keeping forensically valuable dental records? doi: 10.1111/adj.12316.

2. Charangowda BK. (2010) Dental records: an overview. J Forensic Dent Sci; 2(1):5-10.

3. Devadiga A. (2014) What's the deal with dental records for practicing dentists? Importance in general and forensic dentistry. J Forensic Dent Sci; 6 (1):9-15.

4. Harchandani N, Marathe S, Hebbale M, UlNisa S, Hiremutt D. (2014) Awareness of Forensic Odontology among General Dental Practitioners in Pune - A Cross- sectional Study. J Adv Med Dent Scie Res;2(3):10-16

5. Nagarajappa, R. Mehta, M. Shukla, N. Tuteja, JS. Bhalla, A. (2014) Awareness of forensic odontology among dental practitioners in Kanpur city, India: a KAP study, J Dent Res Updates;1(1):6-12

6. Radhakrishna RB. (2007)Tips for Developing and Testing Questionnaires/Instruments. Journal of Extension, 28(2). Available at: http://www.joe.org/joe/2007february/tt2.php.

7. Preethi S, Einstein A, Sivapathasundharam B (2011) Awareness of forensic odontology among dental practitioners in Chennai: A knowledge, attitude, practice study, India, Journal of forensic dental sciences, 3(2): 63-66

8. Schaeffer RL, Mendenhall W, Ott L. (1990) Elementary Survey Sampling, Fourth Edition. Duxbury Press, Belmont, California.

9. Sharma, A. Shokeen, S. Arora, R. Dhaginakatti, SA. (2015) Survey on knowledge, attitude and practice of forensic odontology among private dental practitioners in Ghaziabad city, India, J Dent Specialities, 3(1): 4347. 